\title{
Erratum zu: „Die Landesparlamente im Zeichen der Emergency Politics in der Corona-Krise“
}

\section{Benjamin Höhne}

Online publiziert: 1. Februar 2022

(C) Der/die Autor(en) 2022

\section{Erratum zu:}

\section{Z Politikwiss 2021}

https://doi.org/10.1007/s41358-021-00310-2

Bei der online first Publikation dieses Beitrages wurde versehentlich eine in der HTML-Version sichtbare Article Note nicht im PDF übernommen; die Fußnoten von HTML- und PDF-Version stimmten daher nicht überein.

Der Beitrag wurde korrigiert.

Funding Open Access funding enabled and organized by Projekt DEAL.

Open Access Dieser Artikel wird unter der Creative Commons Namensnennung 4.0 International Lizenz veröffentlicht, welche die Nutzung, Vervielfältigung, Bearbeitung, Verbreitung und Wiedergabe in jeglichem Medium und Format erlaubt, sofern Sie den/die ursprünglichen Autor(en) und die Quelle ordnungsgemäß nennen, einen Link zur Creative Commons Lizenz beifügen und angeben, ob Änderungen vorgenommen wurden.

Die Online-Version des Originalartikels ist unter https://doi.org/10.1007/s41358-021-00310-2 zu finden.

Dr. Benjamin Höhne ( $\triangle)$

Institut für Parlamentarismusforschung, Mauerstr. 83/84, 10117 Berlin, Deutschland

E-Mail: hoehne@iparl.de

Arbeitsstelle „Politische Soziologie der Bundesrepublik Deutschland“, Freie Universität zu Berlin, Otto-Suhr-Institut, Ihnestraße 21, 14195 Berlin, Deutschland 
Die in diesem Artikel enthaltenen Bilder und sonstiges Drittmaterial unterliegen ebenfalls der genannten Creative Commons Lizenz, sofern sich aus der Abbildungslegende nichts anderes ergibt. Sofern das betreffende Material nicht unter der genannten Creative Commons Lizenz steht und die betreffende Handlung nicht nach gesetzlichen Vorschriften erlaubt ist, ist für die oben aufgeführten Weiterverwendungen des Materials die Einwilligung des jeweiligen Rechteinhabers einzuholen.

Weitere Details zur Lizenz entnehmen Sie bitte der Lizenzinformation auf http://creativecommons.org/ licenses/by/4.0/deed.de. 